\title{
Spatiotemporal scaling of North American continental interior wetlands: implications for shorebird conservation
}

\author{
Gene Albanese - Craig A. Davis • \\ Bradley W. Compton
}

Received: 1 December $2011 /$ Accepted: 24 September 2012/Published online: 4 October 2012

(C) The Author(s) 2012. This article is published with open access at Springerlink.com

\begin{abstract}
Within interior North America, erratic weather patterns and heterogeneous wetland complexes cause wide spatio-temporal variation in the resources available to migrating shorebirds. Identifying the pattern-generating components of landscape-level resources and the scales at which shorebirds respond to these patterns will better facilitate conservation efforts for these species. We constructed descriptive models that identified weather variables associated with creating the spatio-temporal patterns of shorebird habitat in ten landscapes in north-central Oklahoma. We developed a metric capable of measuring the dynamic composition and configuration of shorebird habitat in the region and used field data to empirically estimate the spatial scale at which shorebirds respond to the amount and configuration of habitat. Precipitation, temperature, solar radiation and wind speed best
\end{abstract}

G. Albanese - C. A. Davis

Department of Natural Resource Ecology and

Management, Oklahoma State University, Stillwater,

OK, USA

G. Albanese ( $\square)$

Division of Biology, Kansas Cooperative Fish \& Wildlife Research Unit, Kansas State University, 211 Leasure Hall, Manhattan, KS 66502-0102, USA

e-mail: Albanese@KSU.edu

B. W. Compton

Department of Environmental Conservation, Holdsworth Natural Resource Center, University of Massachusetts,

Amherst, MA, USA explained the incidence of wetland habitat, but relationships varied among wetland types. Shorebird occurrence patterns were best explained by habitat density estimates at a $1.5 \mathrm{~km}$ scale. This model correctly classified $86 \%$ of shorebird observations. At this scale, when habitat density was low, shorebirds occurred in $5 \%$ of surveyed habitat patches but occurrence reached $60 \%$ when habitat density was high. Our results suggest scale dependence in the habitat-use patterns of migratory shorebirds. We discuss potential implications of our results and how integrating this information into conservation efforts may improve conservation strategies and management practices.

Keywords Scaling $\cdot$ Multi-scale $\cdot$ Scale dependence - Landscape structure - Wetland cluster . Shorebird habitat - Migration - Landscape metric . Weather patterns $\cdot$ Prairie

\section{Introduction}

Environmental variation concurrently influences the response of biological communities at multiple spatial scales, and a primary objective of landscape ecology is to determine the role scale plays in influencing ecological patterns and processes (Turner 2005). Broad and fine-scale dynamics determine the composition of species within a biological community 
(Ricklefs 1987; Cushman and McGarigal 2004a) and observed patterns in the abundance of organisms depends on the spatial and temporal scale of observations (Allen and Starr 1982; Carlile et al. 1989; Turner et al. 2001). Moreover, organisms function within a range of scales, especially within and among different life history stages such as breeding, dispersal and migration (Addicott et al. 1987; Lindenmayer 2000; Moore 2000).

To understand species-habitat relationships, researchers must consider the scale of environmental patterns and understand how species are affected by these patterns at different scales (Wiens 1989; Levin 1992; Turner 2005). We often limit our understanding of species-habitat relationships by only examining them at one or a few arbitrarily chosen scales that may not be among the range of scales unique to the phenomenon of interest (Wheatley and Johnson 2009). Failure to account for scale-dependent influences may confound and confuse interpretation of results and may make generalizations about organisms inappropriate (Wiens 1989; Cushman and McGarigal 2004b). Alternatively, scaling techniques can be used to examine how species-habitat relationships vary with scale and to identify the scales at which landscape patterns are relevant to target species (Wiens 1989; Holland et al. 2004). These techniques allow researchers to vary the scale of analysis for habitat components and compare the strength of species-habitat relationships among scales. By examining species responses to habitat patterns among scales, we can better define the scales at which these patterns are biologically meaningful (Wiens 1989). Knowledge of biologically appropriate research scales can better facilitate conservation and management efforts and comparison among studies.

Within the Southern Great Plains of N. America, many shorebird species are associated with wetland habitats during migration and primarily rely on saturated soils and shallow water within and around wetlands to acquire food resources (Davis and Smith 1998). Migrating shorebirds encounter complexes of heterogeneous wetland clusters composed of wetlands with different inundation periods (e.g., seasonal, temporary, and permanent hydroperiods) and different wetland types (e.g., lacustrine, riverine, palustrine and anthropogenic-created systems) (Naugle et al. 2000; Johnson et al. 2010). Shorebirds use a variety of these wetland habitats as stopover sites to replenish energy reserves that are critical to successfully complete migration (Skagen and Knopf 1993). However, the wetland habitats available for migratory shorebirds can vary widely depending on seasonal and annual weather patterns because capricious weather patterns produce an unstable wetland landscape with transient and unpredictable resources (Skagen et al. 2008a). For example, severe and erratic weather patterns in the Southern Great Plains of N. America can produce highly dynamic wetland clusters. The region is subject to extreme dry and wet periods (Woodhouse and Overpeck 1998), and seasonal weather systems consist of fast moving and severe storm cells that can rapidly inundate relatively small and discrete areas (Ashley et al. 2003; OCS 2010). During dry periods, permanent and semi-permanent wetlands provide abundant shorebird habitat as mud becomes exposed in lakes, rivers, and ponds, but shallow temporary wetlands such as ephemeral pools and agricultural sheetwater become rare as dry conditions persist. However, these temporary wetlands can provide habitat after heavy precipitation and during wet periods when the exposed mud of more permanent wetlands becomes inundated. Thus, migrating shorebirds encounter a spatially and temporally shifting mosaic of habitat conditions during migration along with unpredictable habitats and food supplies (Skagen and Knopf 1993; Skagen et al. 2008a). As a result, the occurrence and movement patterns of migratory shorebirds through interior North America can vary greatly within and among seasonal and annual migration periods (Colwell 2010).

Wetlands used by migratory shorebirds within central North America have been severely impacted by the rapidly changing landscape. For example, it is estimated that $50-85 \%$ of the wetlands in the Southern Great Plains have been destroyed since the 1780s (Dahl and Allord 1996) and most of the remaining wetlands have little legal protection (Haukos and Smith 2003; van der Valk and Pederson 2003). Moreover, because these wetlands are embedded within agricultural landscapes, many of them are degraded by agricultural practices that increase sedimentation and nutrient and contaminant accumulation (Luo et al. 1997; Detenbeck et al. 2002; Skagen et al. 2008b), change vegetation structure and composition (Smith and Haukos 2002) and negatively impact invertebrate prey resources (Davis and Bidwell 2008). Alteration of hydrological regimes for crop and livestock production and waterfowl management also 
impacts the suitability of wetlands for foraging shorebirds (Taft et al. 2002; Koper and Schiemgelow 2006b). More recently, predictions of climate change and more intensive agriculture suggest continued alteration and loss of prairie wetlands (Tilman et al. 2001; Johnson et al. 2010). With nearly half of North American shorebird species believed to be declining (Brown et al. 2001; Morrison et al. 2001) and evidence that population limitation partly occurs during migration (Baker et al. 2004; Morrison 2006), these largescale habitat changes have raised serious concerns about maintaining an adequate network of stopover sites for migrant shorebirds (Skagen 2006).

Conservation efforts for transcontinental shorebird migrants need to develop approaches that identify landscapes that provide critical wetland habitat and incorporate the shifting distributions of habitats and birds on the landscape (Skagen et al. 2005). Understanding the dynamic relationship between weather patterns and wetland habitat is essential to these efforts. Predictions of climate change make understanding the effect of current weather patterns on the spatial distribution and availability of wetland habitats even more imperative. However, our current understanding of the relationship between environmental patterns and how migratory shorebirds respond to these patterns across different spatial and temporal scales is inadequate for the development of conservation strategies (Skagen et al. 2005). Heterogeneous wetland complexes and the broad dispersion and erratic occurrence of migratory shorebirds throughout the Southern Great Plains make a quantitative evaluation of shorebird-habitat relationships at appropriate spatio-temporal scales challenging. Alternatively, the effectiveness of site-based approaches is limited because shorebirds typically exhibit low site fidelity and greater opportunism as a consequence of the unpredictable nature of suitable habitat (Skagen et al. 2008a; Colwell 2010). To meet these challenges, an effective approach must consider the relationship between weather patterns and the distribution of wetland habitats among landscapes over time, and the response of shorebirds to these patterns among a range of scales. However, we are unaware of any studies that have integrated scaling principles into an experimental design used to describe how these relationships affect the distribution of migratory shorebirds.

This study examined the relationship between shorebird habitat density and shorebird distribution among ten broad scale landscapes in north-central
Oklahoma. Our objectives were to: (1) Construct descriptive models that identified weather variables associated with creating the spatio-temporal patterns of shorebird habitat, (2) develop a metric capable of measuring the dynamic composition and configuration of shorebird habitat in the region, and (3) use field data to empirically estimate the spatial scale at which shorebirds respond to the amount and configuration of habitat. Specifically, we developed a geographic information system (GIS) that identified areas of potential shorebird habitat within each landscape. We performed successive surveys of these areas for the presence of shorebirds and habitat within different wetland types. We used habitat data to calculate estimates of the density of shorebird habitat within landscapes over time. The relationship between shorebird occurrence data and habitat density estimates were modeled to assess the validity of the habitat density estimates and to identify the spatial scale(s) at which shorebirds had the strongest relationship with habitat density.

\section{Methods}

Study area and organisms

We studied shorebird migration in north-central Oklahoma, US. The study area encompassed ten counties that occupied a total area of $24,372 \mathrm{~km}^{2}$ (Fig. 1a). Historically, this landscape was comprised of mixed-grass prairie, but now the landscape is dominated by rangeland and cropland (ODWC 2006). The region contains a variety of palustrine, lacustrine, and riverine wetlands (Henley and Harrison 2000).

Although many different shorebird species of the order Charadiformes may be encountered during migration through north-central Oklahoma, our research focused on members of two suborders, Scolopaci and Charadrii (e.g., sandpipers and plovers). These suborders contain a wide range of species with different habitat associations, however, this research was restricted to those species that migrate through the study area and rely on wetlands as stopover sites during migration. The spring shorebird migration period within the study area begins during late February and ends in early June, while the fall migration period begins in mid-July and ends in October. 


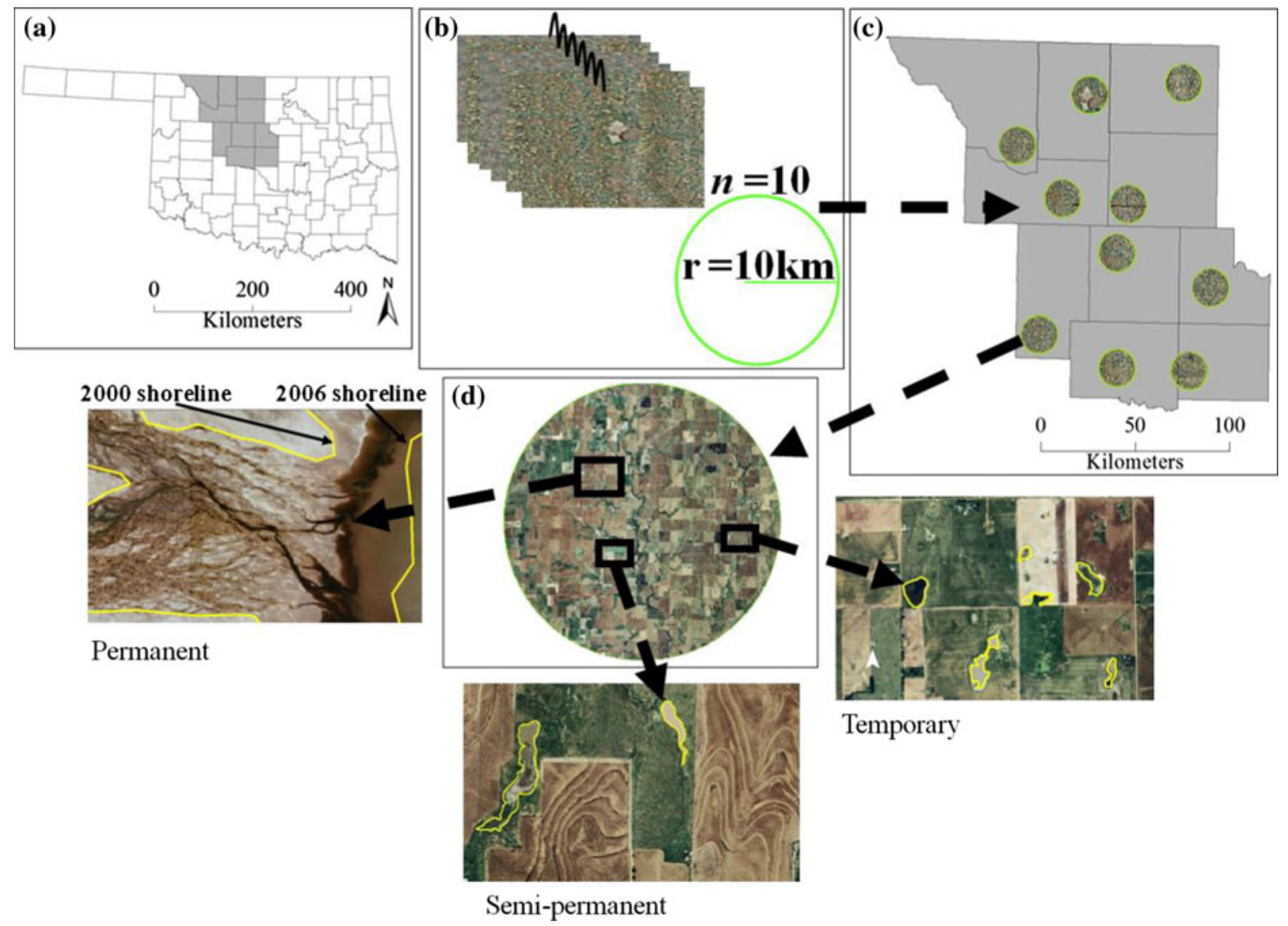

Fig. 1 The study area is indicated by the gray counties within the map of Oklahoma, US (a). b-d Depict the acquisition and assemblage of the base data layers (b), the placement of broadscaled units (BSU) within the study area (c), and the

Geographic information system (GIS)

We used Environmental Systems Research Institute's (ESRI) ArcGIS 9.0 (1999-2004) GIS software to assemble base data layers for each county that included countywide 1:25,000 USGS topographical image mosaics and countywide mosaics of $1.0 \mathrm{~m}$ resolution 1:12,000 digital ortho-image quarter quadrangles (DOQQs). We assembled DOQQs for 6 years (2000, 2003-2006, and 2008) as base data (Fig. 1b). Generally below average precipitation and less shorebird habitat characterized the 2004, 2005 and 2006 images, while above average precipitation and abundant shorebird habitat characterized 2000, 2003, and 2008 images (OCS 2010).

Within the study area, we randomly placed ten $10-\mathrm{km}$ radius circles that we designated as broad-scale examination of BSUs for shorebird habitat (d). All identified shorebird habitat was delineated as a discrete polygon and classified into one of three inundation classes

experimental units (BSU) to represent the total area a migrant shorebird may traverse to locate foraging habitat during a stopover event (Fig. 1c). The size of BSUs was based on radio telemetry research conducted on migrant shorebirds in the Midwestern US that found $90 \%$ of radio-tagged birds $(n=110)$ never traveled $>10 \mathrm{~km}$ from their release site during a stopover event (Farmer and Parent 1997).

Within each broad-scale unit, we visually located each potential habitat patch and delineated them as fine-scale experimental units (FSU) using the GIS (Fig. 1d). We defined shorebird habitat as areas that potentially contain saturated substrate and shallow water $(<16 \mathrm{~cm})$ within wetlands and around wetland edges. Because this study was restricted to those species that rely on wetlands as stopover sites, nonhabitat was any area surrounding potential habitat that 
did not meet these criteria, i.e., dry upland areas. We defined a FSU as a discrete area of contiguous potential shorebird habitat that was surrounded by a matrix of non-habitat during the study period. To delineate FSUs, we systematically examined the entire extent of all base layer DOQQs within each BSU. When a discrete patch of shorebird habitat was identified, it was categorized into one of three inundation classes (temporary, semi-permanent, or permanent) and delineated as a polygon. Temporary, semi-permanent, and permanent classes were defined as habitat present only during wet years, not present in at least one dry year, and present in all years from 2000 to 2008 , respectively. Wet and dry years were determined using county climatic data summaries of precipitation data measured from 1971 to 2000 (OCS 2010) and visual assessments of all DOQQs.

The FSU boundaries delineated for temporary and semi-permanent inundation classes encompassed the greatest contiguous spatial extent of potential shorebird habitat among the series of DOQQs (Fig. 1d). The spatial extent between the lowest shoreline edge and the highest shoreline edge of a wetland area among the DOQQs formed the boundaries of FSUs in the permanent class (Fig. 1d). Because of logistical constraints, we did not delineate discrete potential habitat patches $<1,000 \mathrm{~m}^{2}$ or areas within channeled waterways $<30 \mathrm{~m}$ wide. We further improved the accuracy of our data layers by verifying and refining all boundaries and habitat classifications with field surveys.

\section{Field methods}

During each migration period (fall 2007, 2008 and spring 2007, 2008, 2009), we conducted four shorebird surveys on a unique sample of randomly selected (without replacement) FSUs within each BSU. Each migration period was divided into four 23-day intervals. We estimated a sample size of $13 \%$ of the total potential shorebird habitat area in each BSU would be required to detect an effect in shorebird occurrence using an a priori regression power analysis (Lenth $\mathrm{R}$ 2006) for sample size ( $\alpha=0.05,1-\beta=0.95)$. The variance and effect size estimates used in the power analysis were calculated from pilot study data collected during the spring 2007 migration period within randomly selected FSUs $(n=353)$. We therefore surveyed $13-15 \%$ of the total area of FSUs in each
BSU during each 23-day interval. Within each BSU, the proportion of FSU area sampled in each inundation class was equal to the proportion of the total habitat area that each inundation class encompassed.

We conducted shorebird surveys from a vehicle or on foot, depending on the visibility or location of the FSU, during daylight hours on randomly chosen dates within an interval. After arriving at a FSU, the observer waited $5 \mathrm{~min}$ before initiating a survey. Each FSU $\leq 1$ ha was surveyed for a minimum of $5 \mathrm{~min}$ during a visit to standardize sampling effort. We added equal survey time for each additional hectare of habitat surveyed within a FSU. Shorebirds were observed with a $10 \times 60$ spotting scope or $8 \times 40$ binoculars. All shorebirds observed in the FSU were identified and counted.

During each field survey, we also estimated percent total cover of shorebird habitat (saturated substrate and shallow water $<16 \mathrm{~cm}$ ) within each FSU and further classified each FSU into one of the following wetland categories: wastewater impoundment, riverine, lacustrine, palustrine and floodwater (Cowardin et al. 1979). To estimate shorebird habitat cover, a traditional cover-class scheme was used which included the following cover classes: 0, 1-5, 6-25, 26-50, 51-75, 76-95, and >95 \% (e.g., Domin 1928; Daubenmire 1968). Cover-class midpoints were used in the final analysis and each FSU was classified into a distinct shorebird habitat type using the combined inundation class and wetland category assignments (e.g. permanent riverine).

We also collected daily weather data from ten Oklahoma Mesonet weather stations. The Oklahoma Mesonet program consists of a network of 119 automated observation stations that measure seventeen weather and soil variables several times daily (OCS 2010). The station closest to the centroid of a BSU was selected to collect data associated with that unit.

Weather patterns and shorebird habitat

For this analysis, we summarized daily weather variables and shorebird habitat incidence $(p)$ estimates by the survey interval in which they were collected $(n=166)$. Estimates of $p$ were the proportion of sampled FSUs of each habitat type with shorebird habitat present during a survey interval of a BSU. Initially, we used Spearman rank correlation coefficients to select a subset of non-redundant weather 
variables among the seventeen weather variables initially collected. Weather variables with correlations $>0.50$ were considered redundant. Among redundant variables, we selected the variable with the strongest correlation with the incidence of shorebird habitat types. Average daily temperature, total precipitation, average daily wind speed, average daily maximum barometric pressure and average total daily solar radiation were selected for the final analysis. The direction of the correlations between the shorebird habitat types and the selected weather variables were similar within the permanent and temporary inundation classes. Therefore, we pooled habitat types within these inundation classes for the final analysis. Because inverse correlations existed among habitat types in the semi-permanent inundation class and the selected weather variables, we split these observations into two corresponding groups for the final analysis. Data associated with wastewater impoundment habitats were not included because anthropogenic management activities, not weather patterns, were the main cause of variability for this habitat type.

We used linear time-series regression models (Ives and Zhu 2006) to describe patterns in $p$ using the selected weather variables. All data were tested for normality and homogeneity of variance and transformed when necessary. To account for temporal autocorrelation among these data, we fitted models with ordered autoregressive structures [AR (1)] (Ives and Zhu 2006; Zuur et al. 2009) and used maximum likelihood estimation to estimate model parameters. This approach accounted for correlation in each habitat variable among sequential surveys within BSUs, where a given $p$ estimate at time $(t)$ was dependent on the $p$ estimate at $(t-1)$. For each timeseries, we used subsequent observed values to estimate $p$ for $t(0)$. The fit of all global models to the data was assessed using residual deviance goodness-of- fit tests.

To identify which models best explained observed patterns in $p$ for each habitat type, we used an information theoretic framework to compare alternative models (Burnham and Anderson 2002). The alternative models represented all additive combinations of each global model and a null model. We used Akaike's information criterion adjusted for small sample sizes (AICc) to compare the relative ability of alternative models to explain observed patterns. We calculated $\triangle \mathrm{AICc}$ and Akaike weights $\left(w_{i}\right)$, to evaluate the support for each model given the data (Burnham and Anderson 2002). We considered all models with a $\triangle \mathrm{AICc}<6$ to have support. We used the AIC weights to calculate model-averaged parameter estimates, summed Akaike weights and $95 \%$ confidence intervals (CI) for each parameter estimate (Burnham and Anderson 2002).

\section{Shorebird habitat metric}

Initially, we used ESRI, ArcGIS 9.0 (1999-2004) GIS software to convert the shorebird habitat layer from vector to raster data. The program converted each $10 \mathrm{~m}^{2}$ of shorebird habitat within a FSU polygon into a raster grid cell and assigned each cell to a specified habitat type. Areas not delineated as shorebird habitat were not assigned to any habitat type. A point was placed on each cell located within a FSU.

We then applied the data to a kernel-density estimation program. Kernel density estimation is a non-parametric analytical technique that generates a smoothed density average for data points over a local neighborhood (Worton 1989; Seaman and Powell 1996). For each survey interval $(n=166)$, we incorporated $p$ estimates for each habitat type into the kernel function. A kernel function of a specified smoothing parameter $(h)$ was placed on each point, with the height determined by $p$ for a given habitat type during an interval. Thus, the density value at distance $\mathrm{x}$ from a FSU with probability $p$ was $\mathrm{fn}(x) \times p$. This method accounted for the different sizes and spatial arrangement of FSUs. Estimates of $p$ were constant across different values of $h$, and different $p$ estimates for each interval were consistent at different distances. Habitat density estimates were calculated for each BSU using $h$ parameter values at $500 \mathrm{~m}$ intervals from $500 \mathrm{~m}$ to $4 \mathrm{~km}$ for all survey intervals of the study (Fig. 2a, g-i). The program assigned a density estimate to each $10 \mathrm{~m}^{2}$ cell within the broad-scale unit. Habitat density estimates ranged from zero to one where a value of one equaled complete cover of shorebird habitat at the given scale. The density estimates for each FSU used in the analysis was the density value at the centroid of FSU.

We used classification tree analysis (CTA) (Breiman et al. 1984) to model the relationship between shorebird occurrence in a FSU and the habitat density estimates calculated from the different $h$ parameter values. We performed this analysis with data from 166 survey intervals collected among the ten BSUs. Total 

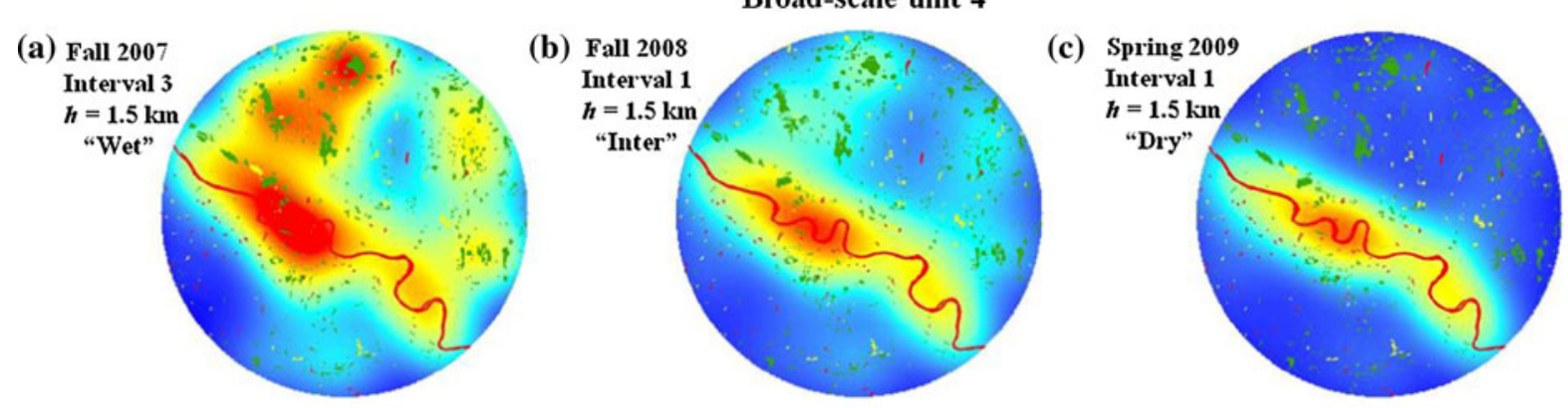

Broad-scale unit 9
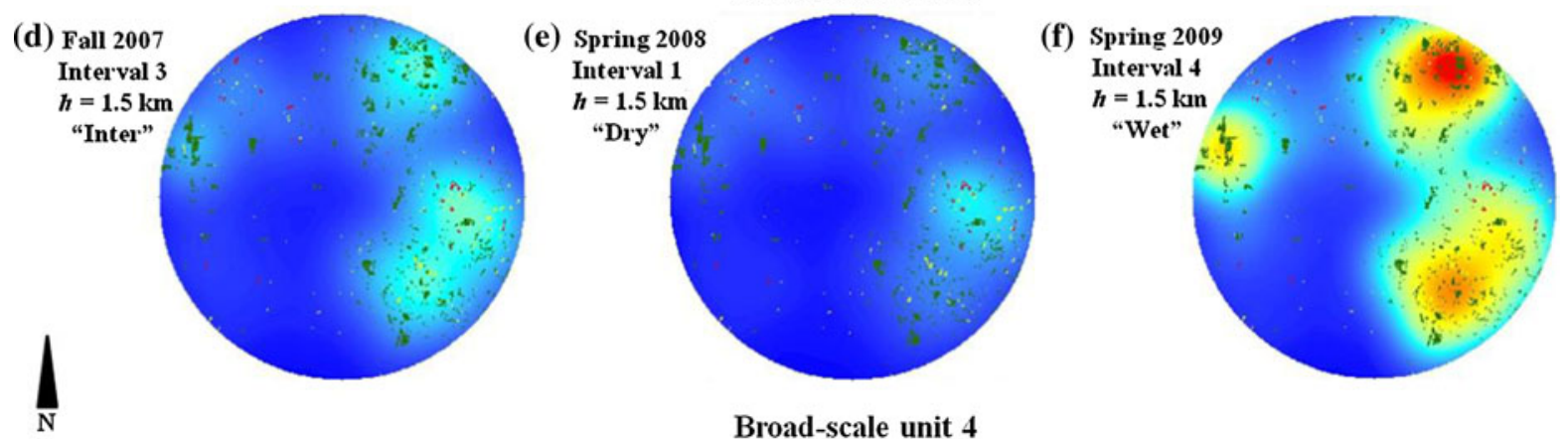

Broad-scale unit 4
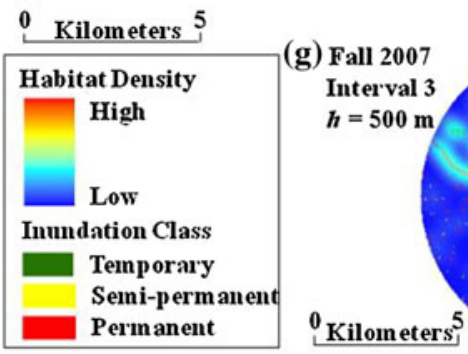

Fig. 2 a-f Habitat density surfaces calculated using habitat incidence estimates collected in the study area and kernel density estimation with scalar argument $(h)$ held constant $(h=1.5 \mathrm{~km})$. Habitat incidence $(p)$ estimates were the proportion of sampled fine-scale units of a habitat type with habitat present during a survey interval of a broad-scale unit (BSU). A sample of three of the sixteen surfaces produced for each of two

habitat area for each FSU surveyed during the 166 intervals was also calculated and modeled for comparison. We chose CTA because it is appropriate for analyzing complex ecological data with a non-standard data structure, it can detect non-linear responses and complex interactions, and it is robust to outliers (De'ath and Fabricius 2000).

We built classification trees using the Gini Index, with priors set to equal. We used 10-fold cross validation, repeated 1,000 times to smooth the estimated error rates, and then used the $1-$ SE rule to select the pruned tree size (Breiman et al. 1984). To

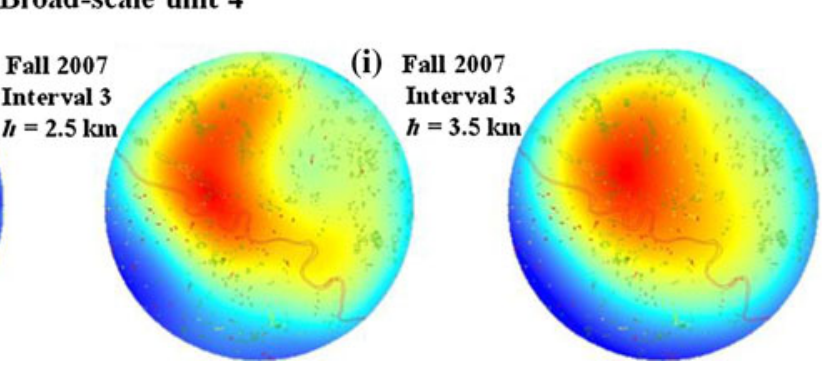

different BSUs (a-f, respectively) are shown in sequence from spring 2007 thru spring 2009. The general conditions are noted as wet, dry or intermediate (inter) for each image. a and $\mathbf{g}-$ i Show habitat density surfaces calculated with $p$ held constant and $h$ varied $(h=1.5 \mathrm{~km}, 500 \mathrm{~m}, 2.5 \mathrm{~km}$, and $3.5 \mathrm{~km}$, respectively). Shorebird habitat is shown by inundation class

evaluate the overall classification tree performance we calculated the correct classification rate (CCR) and chance-corrected classification accuracy statistic (Kappa) of each tree. In addition, we derived a $p$ value for each pruned tree using Monte Carlo resampling. We created 1,000 trees through random permutation of the data and compared the CCR of our classification trees to the distribution of CCRs.

Because our density estimates were based only on the arrangement and incidence of shorebird habitat contained within the boundaries of BSUs, we were concerned about under-estimating the density of FSUs 
located close to boundaries. We therefore conducted an uncertainty analysis to examine the effects of this bias on the final results. We used the methods previously described to produce density surfaces for each BSU but we included an edge correction factor. The correction factor was developed by placing kernel functions on raster cells beyond BSU boundaries that affected the breadth of the "window" used to calculate each density estimate. The values of kernel functions within "boundary" FSUs were divided by one minus the values of the kernel functions built for the correction factor. This had the effect of reflecting existing data from within a BSU beyond its boundaries and thus increasing the density values of FSUs located near boundaries. We then conducted a separate CTA using these density estimates and compared these results to those conducted on the data calculated without the edge correction factor. The arrangement, splitting rules, CCRs and Kappa statistics of each corresponding pair of models were very similar (e.g., Kappa varied by an average of $<4 \%$ ). The density estimates calculated without the edge correction factor were used in the final analysis because the method was simpler and the density estimates were based solely on field data.

In addition, we performed a cross validation among the seasons included in this study to test the robustness of the final tree model. Splitting and model selection criteria remained constant for all constructed trees and were the same as those previously described. We first performed separate classification tree analyses on data from each season. We compared the results of these trees to each other to check for possible trends between seasons. The classification trees were similar among seasons and partitioned the data at comparable habitat density values. Classification trees had an average CCR of $85.7 \%$. We then conducted a five-fold cross validation using each season's observations to predict the response of the other season. The average CCR of the observed verusus predicted was $86.0 \%$. Based on these results, we pooled all season's observations for the final analysis.

As part of our final analysis, we performed a 10 -fold cross validation to assess the potential effects of each broad-scale unit on the final model. For this cross validation, we constructed a tree from nine of the ten BSUs and used this model to predict the response of the tenth unit and repeated this process ten times. We calculated the CCR of each classification tree and each unit's predicted response. Finally, we compared the results among classification trees to assess the influence of each BSU on the final tree model. All analyses were conducted using R 2.12.1 (R Development Core Team 2010) software.

\section{Results}

During this study, we surveyed 14,444 FSUs that represented a total area of 26,632 ha. At the time of survey, shorebird habitat was present in 8,337 FSUs. We observed shorebirds in 1,321 of the FSUs and encountered 29 shorebird species during surveys (Table 1).

Weather patterns and shorebird habitat

For temporary habitats, the variables total daily precipitation and average daily temperature were included among the best approximating models (Table 2). Temporary habitats were positively related to increasing precipitation and negatively related to increasing temperature. The sums of the Akaike weights suggest that the amount of precipitation was the most important predictor of temporary habitat incidence. The model set selected to predict semipermanent floodwater habitat only contained the variable total precipitation. As with temporary habitat, semi-permanent floodwater habitat was positively correlated to precipitation. For semi-permanent lacustrine, riverine and palustrine habitats, the model set selected included the variables total precipitation, average daily wind speed, average daily temperature and average total daily solar radiation. The relationship between these habitats and precipitation was negative and these habitats were positively correlated with solar radiation, temperature and wind speed. The variables total precipitation, average daily wind speed and average daily temperature were among the "best model" set of the incidence of permanent shorebird habitat and the sums of the Akaike weights indicate that temperature was the most important predictor. Incidence of permanent habitat was negatively correlated with precipitation, but positively with temperature and wind speed.

We demonstrate the relationship between the density of shorebird habitats and weather patterns during the study using a subset of density surfaces 
Table 1 List of migratory shorebird species and migration period during which each species were encountered within shorebird habitat units located in north-central Oklahoma, US, 2007-2009

\begin{tabular}{|c|c|c|}
\hline Species & Spring & Fall \\
\hline Black-bellied Plover (Pluvialis squatarola) & $\mathrm{X}$ & $\mathrm{X}$ \\
\hline American Golden-Plover (Pluvialis dominica) & $X$ & $\mathrm{X}$ \\
\hline $\begin{array}{l}\text { Semipalmated Plover (Charadrius } \\
\text { semipalmatus) }\end{array}$ & $\mathrm{X}$ & $\mathrm{X}$ \\
\hline American Avocet (Recurvirostra americana) & $\mathrm{X}$ & $\mathrm{X}$ \\
\hline Black-necked Stilt (Himantopus mexicanus) & $\mathrm{X}$ & $\mathrm{X}$ \\
\hline Willet (Tringa semipalmata) & $X$ & $\mathrm{X}$ \\
\hline Lesser Yellowlegs (Tringa flavipes) & $\mathrm{X}$ & $\mathrm{X}$ \\
\hline Greater Yellowlegs (Tringa melanoleuca) & $\mathrm{X}$ & $\mathrm{X}$ \\
\hline Solitary Sandpiper (Tringa solitaria) & $X$ & $\mathrm{X}$ \\
\hline Whimbrel (Numenius phaeopus) & $\mathrm{X}$ & \\
\hline Long-billed Curlew (Numenius americanus) & $X$ & \\
\hline Hudsonian Godwit (Limosa haemastica) & $X$ & \\
\hline Marbled Godwit (Limosa fedoa) & $\mathrm{X}$ & $\mathrm{X}$ \\
\hline Ruddy Turnstone (Arenaria interpres) & $\mathrm{X}$ & $\mathrm{X}$ \\
\hline Red Knot (Calidris canutus) & & $\mathrm{X}$ \\
\hline Sanderling (Calidris alba) & $\mathrm{X}$ & $\mathrm{X}$ \\
\hline Dunlin (Calidris alpina) & $X$ & \\
\hline Semipalmated Sandpiper (Calidris pusilla) & $\mathrm{X}$ & $\mathrm{X}$ \\
\hline Western Sandpiper (Calidris mauri) & $\mathrm{X}$ & $\mathrm{X}$ \\
\hline Least Sandpiper (Calidris minutilla) & $\mathrm{X}$ & $\mathrm{X}$ \\
\hline White-rumped Sandpiper (Calidris fuscicollis) & $\mathrm{X}$ & \\
\hline Pectoral Sandpiper (Calidris melanotos) & $\mathrm{X}$ & $\mathrm{X}$ \\
\hline Baird's Sandpiper (Calidris bairdii) & $X$ & $\mathrm{X}$ \\
\hline $\begin{array}{l}\text { Buff-breasted Sandpiper (Tryngites } \\
\text { subruficollis) }\end{array}$ & $X$ & $\mathrm{X}$ \\
\hline $\begin{array}{l}\text { Long-billed Dowitcher (Limnodromus } \\
\text { scolopaceus) }\end{array}$ & $\mathrm{X}$ & $\mathrm{X}$ \\
\hline Wilson Snipe (Gallinago delicate) & $\mathrm{X}$ & $\mathrm{X}$ \\
\hline Stilt Sandpiper (Calidris himantopus) & $\mathrm{X}$ & $\mathrm{X}$ \\
\hline Wilson's Phalarope (Phalaropus tricolor) & $\mathrm{X}$ & $\mathrm{X}$ \\
\hline Red-necked Phalarope (Phalaropus lobatus) & $\mathrm{X}$ & $\mathrm{X}$ \\
\hline
\end{tabular}

Shorebird habitat was defined as shallow water $(<16 \mathrm{~cm})$ and saturated substrate within and surrounding wetlands

calculated for sixteen intervals in two BSUs (Fig. 2). The first BSU we depict contained both large amounts of potential temporary floodwater habitat in its northern half and permanent riverine habitat along the central interior (Fig. 2a-c). The eastern side of the second BSU contained a potentially large amount of temporary floodwater habitat, but small amounts of other habitat types (Fig. 2d-f). Conditions were wet during fall 2007 in the first unit and during spring 2009 in the second unit. Correspondingly, these surfaces illustrate a sequentially inverse pattern of low and high habitat density in the areas dominated by temporary floodwater habitats during wet periods. When conditions were drier in the first unit during the spring 2009, only the permanent riverine habitat feature within the landscape contained areas of high-density habitat (Fig. 2a-c). Likewise, when conditions were drier in second unit during fall 2007 and spring 2008, high density habitat was absent (Fig. 2e, f). Similar fluctuations in the distribution of low and high density habitat were evident within sequences of density surfaces among the other BSUs in the study. The scale of these fluctuations varied with the $h$ value used in the kernel function (Fig. 2a, g-i).

Spatial scaling and shorebird occurrence

The results of the classification tree models of FSUs occupied versus unoccupied by shorebirds and habitat density calculated using the different scalar arguments or habitat area indicated that the strongest relationship between the occurrence of shorebirds in a FSU and density of shorebird habitat occurred when $h$ was set to $1.5 \mathrm{~km}$ for the kernel density estimation. Among classification tree models, Kappa was lowest when habitat area was used to explain the occurrence of shorebirds. Kappa increased with $h$ until reaching a maximum at $1.5 \mathrm{~km}$ but then declined as the scalar argument was further increased in the kernel function (Fig. 3).

The pruned classification tree model of occupied versus unoccupied FSUs using habitat density with $h=1.5 \mathrm{~km}$ correctly classified 7,154 of the 8,337 observations $(\mathrm{CCR}=86 \%, k=0.61, p \leq 0.001)$ (Fig. 4). Habitat density initially partitioned the observations into two sub-groups $(>0.07$ and $<0.07$ ) and then further partitioned the observations at 0.22 . At low habitat density $(<0.07)$, shorebirds occupied only $5 \%$ of FSUs but this increased to $36 \%$ when density was $>0.07$ but $<0.22$. Shorebird occupancy was highest $(60 \%)$ when habitat density was $>0.22$.

The classification tree models constructed during the 10 -fold cross validation among BSUs were similar and partitioned the data at comparable habitat density values. The average CCR among trees was $84.8 \%$ (range $=79-87 \%)$. However, one model had a single partition at the 0.07 density value and the CCR for this 
Table 2 The summed Akaike weights for weather variables included in the "best model" sets from the time-series regression analyses of the incidence of different wetland

\begin{tabular}{|c|c|c|c|c|}
\hline Habitat class & $\begin{array}{l}\text { Total daily } \\
\text { precipitation }\end{array}$ & $\begin{array}{l}\text { Average daily } \\
\text { wind speed }\end{array}$ & $\begin{array}{l}\text { Average daily } \\
\text { temperature }\end{array}$ & $\begin{array}{l}\text { Average total daily } \\
\text { solar radiation }\end{array}$ \\
\hline Temporary & $(+) 0.95$ & & $(-) 0.53$ & \\
\hline $\begin{array}{l}\text { Semi-permanent } \\
\text { Floodwater }\end{array}$ & $(+) 0.85$ & & & \\
\hline $\begin{array}{l}\text { Semi-permanent } \\
\text { Palustrine } \\
\text { Lacustrine } \\
\text { Riverine }\end{array}$ & (-) 0.07 & $(+) 0.28$ & $(+) 0.71$ & $(+) 0.20$ \\
\hline Permanent & $(-) 0.31$ & $(+) 0.66$ & $(+) 0.98$ & \\
\hline
\end{tabular}

For each habitat class, values are listed for weather variables that were included in the "best model" set $(\Delta \mathrm{AICc}<6)$ and for which the $95 \%$ confidence interval of the parameter estimate did not include zero. The sign of each model-averaged parameter estimate is given in parentheses. Weather variables and shorebird habitat incidence estimates were summarized by the landscape and the survey interval in which they were collected $(n=166)$

${ }^{a}$ Habitat types within the semi-permanent habitat class were split into two groups for the analysis. Habitat types included in each of these groups are listed in italics

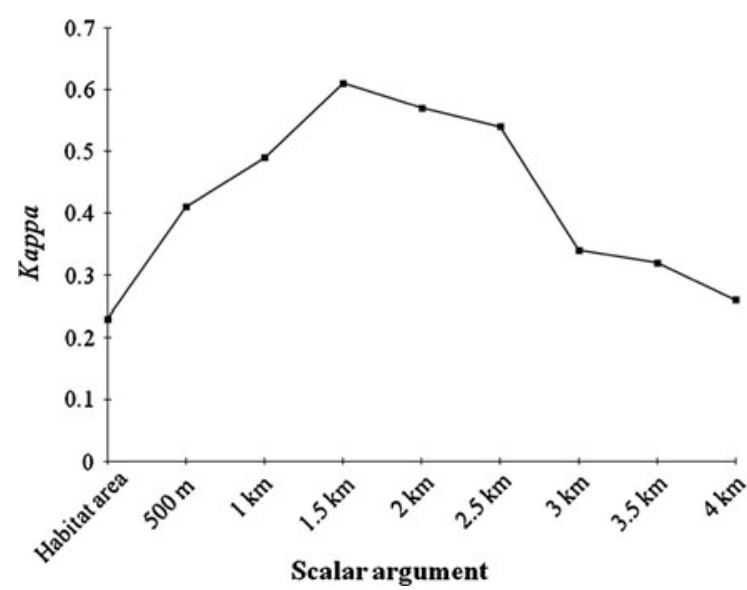

Fig. 3 Plot of the chance-corrected classification accuracy statistic (Kappa) calculated for classification tree models of the relationship between shorebird occurrence and habitat area or density at different spatial scales. Habitat density estimates were calculated using habitat incidence estimates from field data and eight sequential distances at $500 \mathrm{~m}$ intervals for the scalar argument in a kernel density estimation function

tree was the lowest $(\mathrm{CCR}=79 \%)$. This indicates that there was a difference between this BSU and the other BSUs and that the partition at the 0.22 density value was greatly influenced by inclusion of data from this BSU. This was likely due to the presence of the Salt Plains National Wildlife Refuge in this BSU, which maintained a relatively high density of shorebird habitat during the entire length of the study. However, this model still correctly predicted $72 \%$ of the data from this BSU. The average CCR of the observed versus predicted was $88.4 \%$ among all models. These results indicate that our final model was stable and was capable of predicting the occurrence of shorebirds across our large study area.

\section{Discussion}

\section{Spatial scaling}

A continuing priority for ecology is to understand the response of organisms to spatial pattern at multiple scales (Levin 1992; Turner et al. 2001; Turner 2005). Further, the analysis of ecological patterns at multiple scales is preferred because patterns are organism and scale dependent (Wu and Loucks 1995). The identification of points where patterns and processes change along a scale continuum may help identify key shifts in ecological processes and biologically appropriate research scales (Wiens 1989). We show that the ability to predict the occurrence patterns of migrant shorebirds within the Southern Great Plains of N. America depends on the scale at which the landscape structure of shorebird habitat is measured. When we 


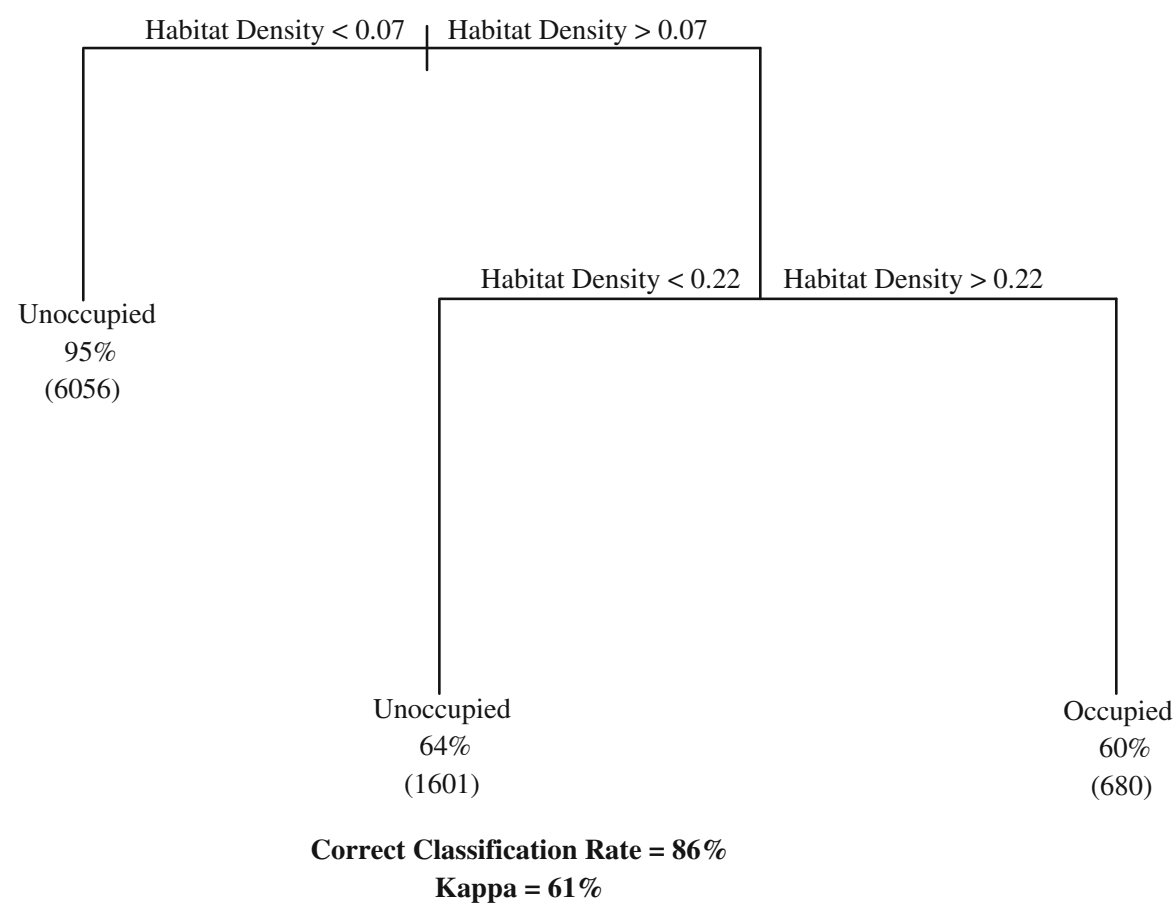

Fig. 4 Pruned classification tree model for the categorical response variable of fine-scale sampling units occupied versus unoccupied by migratory shorebirds. The explanatory variable shorebird habitat density was calculated using kernel density estimation. Habitat probability estimates collected during each survey interval of a broad-scale unit during the study were incorporated into the kernel function and the $h$ parameter for the function was set to $1.5 \mathrm{~km}$. The density value ranged from 0 to

compared degrees of spatial dependence, habitat density was a better predictor of shorebird occurrence than habitat area and the strength of the relationship between shorebird occurrence and habitat density varied with spatial scale. As the distance of the scalar argument in the habitat density metric increased, the degree of spatial dependence concurrently increased, peaked at $1.5 \mathrm{~km}$ and then declined. This suggests that the $1.5 \mathrm{~km}$ scale represents the grain of resource configuration at which migrating shorebirds interact with landscape structure when making settling decisions during migration. These results provide evidence of spatial dependence in species distribution patterns and empirical support for ecological scaling techniques that are currently limited despite increased attention (Wheatley and Johnson 2009).

Although it is interesting to find evidence of spatial dependence in these species, only by doing experimental manipulations can we rigorously determine the
1.0 and the value at the centroid of each sampled fine-scale unit was used in the analysis. Each partition in the classification tree is labeled with the splitting rule. Splitting statements are true to the left and false to the right. Each terminal node is labeled with the dominant response category for that group, the proportion of observations within that category and the number of observations in the group is given in parentheses

processes that influence settlement patterns during migration. Furthermore, other unmeasured factors certainly contributed to the occurrence patterns of migrant shorebirds in the study area. For example, the processes influencing the occurrence patterns of some bird species may be attributed to social drivers rather than the distribution of resources within landscapes (Melles et al. 2009). Additionally, several studies that have compared the effects of different environmental factors at multiple spatial scales and their interactions on bird distribution patterns have demonstrated that the variability within a factor influences its importance within and among scales (Koper and Schiemgelow 2006a; Vergara and Armesto 2009). Thus, a multiscale evaluation of the relative importance of habitat density compared to other potential determinants of migrant shorebird occupancy patterns would provide further insights into the influence of habitat density on habitat-use. 
Implications for migratory shorebirds

We hypothesize that by selecting broad-scale complexes of high-density wetland habitat shorebirds can use more wetland resources with reduced searching cost. Under these conditions, shorebirds have increased access to greater foraging opportunities. Farmer and Parent (1997) came to a similar conclusion when comparing the movements of radio-tagged Pectoral Sandpipers (Calidris melanotos) among three landscapes in the Midwestern US. They found that Pectoral Sandpipers moved more frequently for shorter distances among wetlands in landscapes with greater wetland connectivity. Similar responses have been observed in other organisms. For example, Romero et al. (2009) found that landscape structure influenced beetle movement behaviors in model landscapes and concluded that dispersal costs likely increase with inter-patch distance. Furthermore, the mixture of wetland types within clusters may provide a greater range of exploitable niches for wetland dependent species. Several studies have demonstrated an association between increased species richness and intra wetland proximity for various wetland taxa (Wettstein and Schmid 1999; Uchida and Inoue 2010; Ribeiro et al. 2011), including wetland birds (Naugle et al. 1999; Webb et al. 2010).

Differences among habitat components such as vegetation structure, available exposed mud and water depth within a wetland significantly influence wetland use by migrant shorebirds in the Southern Great Plains of N. America (Davis and Smith 1998). Additionally, positive relationships between migratory shorebird species, wetland area and the amount of wetlands in the surrounding landscape have been documented (Farmer and Parent 1997; Niemuth et al. 2006; Webb et al. 2010). However, inconsistency in the choice of observational scale among these studies has made generalizations regarding the relevance of this habitat component to understanding the habitat-use patterns of these species challenging. In contrast, by examining this component along a scale continuum we identified the spatial scale where habitat structure may be most relevant to the study species. Moreover, scaling relations are generally more consistent and predictable among landscape pattern metrics with changing grain size (Wu 2004). Our results suggest that broad-scale habitat density may also be an important ecological factor to the distribution of shorebirds during migration through the region. Several other studies outside of this study region have also found that indices summarizing the amount and configuration of habitat were important determinants of bird occurrence and abundance patterns (Thogmartin and Knutson 2007; Fletcher and Hutto 2008; Renfrew and Ribic 2008). This generalization may be practical for conservation efforts because our model describes the occurrence patterns of migratory shorebirds at a community level providing a generally applicable management opportunity that can positively affect a range of species with focused conservation resources.

Implications of a changing environment

The relationship between wetland habitat types and weather patterns is complex. Different wetland types responded conversely to the same weather variables and the importance of weather variables differed among wetland types. At any given time within the study area, local and heavy precipitation events created landscapes with extant ephemeral wetland habitats, while other landscapes were rendered barren by extended dry conditions. In the case of more permanent wetlands, the extended dry conditions actually enhanced habitats for shorebirds by creating expanses of shorebird habitat along wetland edges. However, these patterns were not mutually exclusive within and among landscapes but rather existed along a gradient where local weather patterns caused some habitats to dissipate while other habitats became available. Previous investigations of migratory shorebirds in the interior of North America have noted similar trends among ephemeral and semi-permanent wetlands during wet and dry periods (Skagen et al. 2008a). In these systems, the highly dynamic nature and shifting distributions of available habitats makes the availability of specific wetlands unpredictable. Several authors have suggested that these shifting and unpredictable habitat patterns have led to the "hop" migration strategy (Pierisma 1987) and the opportunistic use of habitats by migratory shorebirds passing through the continental interior (Skagen and Knopf 1993; Warnock et al. 1998; Skagen 2006). Our findings support this view. Wetland clusters at broad spatial scales (i.e., $1.5 \mathrm{~km}$ ) were limited by the spatial structure of potential wetland habitat types among landscapes and were transitory because wetland types within complexes responded differently to weather patterns. 
The prevailing theoretical model used to understand the process of stopover selection used by migratory birds implies that birds initially rely on broad-scale cues and progress toward finer-scale characteristics (Hutto 1985; Moore 2000; Petit 2000; Deppe and Rotenberry 2008). Our results suggest that broad-scale clusters of high-density habitat may provide an important initial cue for migratory shorebirds during the process of habitat selection. However, forecasts of a drier and warmer climate for the Southern Great Plains (IPCC 2007) may negatively impact the availability of some wetland types within this region and have important implications at the spatial domain in which migratory shorebirds use broad-scale cues to select stopovers. When future climate warming scenarios were applied to wetland landscapes within the Prairie Pothole Region of North America, models predicted substantial reductions in the availability of ephemeral wetlands among complexes and indicated these wetlands were the most vulnerable to a warmer and drier climate (Johnson et al. 2010). Correspondingly, our results suggest that the incidence of temporary shorebird habitats were positively related to increasing precipitation and negatively related to increasing temperature. Within the continental interior, ephemeral wetlands are critical stopovers for many migratory shorebird species (Davis and Smith 1998; Skagen et al. 2008a) and at broad spatial scales, abundant ephemeral habitats may be particularly important to the landscape-level abundance and richness of shorebirds that migrate intermediate and long distances (Albanese and Davis 2013). A more arid climate may not only limit the availability of these vital wetlands but may also preclude the formation of high-density habitat at the spatial scales at which en route shorebirds use coarselevel cues to select stopovers at the end of migratory flights. We therefore recommend that research on the potential effects of climate warming scenarios be extended to other wetland landscapes of the Southern Great Plains.

\section{Conclusions}

To preserve an adequate network of stopover resources for migrant shorebirds we must recognize the importance of both spatial and temporal dynamics within and among the wetland clusters of a migration stopover network and identify the domains of scale that are relevant to these birds within the region (Skagen et al. 2008a). Our findings indicate that conservation and management of migratory shorebird stopover habitats should aim to provide areas of potentially high-density habitat at a $1.5 \mathrm{~km}$ spatial scale. Preservation of wetland clusters that include a diverse mixture of different wetland types and inundation periods may best ensure that at least some adequate stopover resources are persistently present within this continually changing landscape.

Acknowledgments S. D. Fuhlendorf, B. Luttbeg, S. K. Skagen and P. D. Vickery provided valuable reviews that greatly improved this manuscript. This study was funded by an Oklahoma Department of Wildlife Conservation State Wildlife Grant that was administered through the Oklahoma Cooperative Fish \& Wildlife Research Unit. We gratefully acknowledge additional support provided by Department of Natural Resource Ecology and Management at Oklahoma State University, U. S. Geological Survey and U.S. Fish \& Wildlife Service. We would also like to thank the thousands of private land owners for access to their properties. We thank field assistants R. Torres-Cervantes, L.W. Elmore and A. Nealis, and we especially thank S. D. Albanese, S. K. Albanese, K. Andersson and S. Sullivan whose tireless efforts made this project possible.

Open Access This article is distributed under the terms of the Creative Commons Attribution License which permits any use, distribution, and reproduction in any medium, provided the original author(s) and the source are credited.

\section{References}

Addicott JF, Aho JM, Antolin MF, Padilla DL, Richardson JS, Soluk DA (1987) Ecological neighborhoods: scaling environmental patterns. Oikos 49:340-346

Albanese G, Davis CA (2013) Broad-scale relationship between shorebirds and landscapes in the Southern Great Plains. Auk (in Press)

Allen TFH, Starr TB (1982) Hierarchy: perspectives for ecological complexity. University of Chicago Press, Chicago

Ashley WS, Mote TL, Dixon PD, Trotter SL, Durkee JD, Powell EJ, Durkee JD, Grundstein AJ (2003) Distribution of mesoscale convective complex rainfall in the United States. Mon Weather Rev 131:3003-3017

Baker AJ, Gonzalez PM, Piersma T, Niles LJ, do Nascimento ILS, Atkinson PW, Clark NA, Minton CD, Peck MK, Aarts G (2004) Rapid population decline in Red Knots: fitness consequences of decreased refueling rates and late arrival in Delaware Bay. Proc R Soc Lond (Biol) 271:875-882

Breiman L, Friedman JH, Olsen RA, Stone CJ (1984) Classification and regression trees. Wadsworth International Group, Belmont

Brown S, Hickey C, Harrington B, Gill R (2001) United States shorebird conservation plan, 2nd edn. Manomet Center for 
Conservation Sciences, Manomet. www.fws.gov/shorebird plan/USShorebird/downloads/USShorebirdPlan2Ed.pdf. Accessed 15 Jan 2011

Burnham KP, Anderson DR (2002) Model selection and multimodel inference. Springer-Verlag, New York

Carlile DW, Slalski JR, Batker JE, Thomas JM, Cullinan VI (1989) Determination of ecological scale. Landscape Ecol 2:203-213

Colwell MA (2010) Shorebird ecology, conservation and management. University of California Press, Berkley

Cowardin LM, Carter V, Golet FC, LaRoe ET (1979) Classification of wetlands and deepwater habitats of the United States. USF\&W Service, Biological services program, Washington D.C., USA

Cushman SA, McGarigal K (2004a) Hierarchical analysis of forest species-environmental relationship in the Oregon coast range. Ecol Appl 14:1090-1105

Cushman SA, McGarigal K (2004b) Patterns in the species environment relationship depend on both scale and choice of response variables. Oikos 105:117-124

Dahl TE, Allord GJ (1996) History of wetlands in the conterminous United States. In: Fretwell JD et al (eds) National summary on wetland resources. USGS, Springfield, pp 19-26

Daubenmire R (1968) Plant communities: a textbook of synecology. Harper and Row, New York

Davis CA, Bidwell JR (2008) Response of aquatic invertebrates to vegetation management and agriculture. Wetlands 28:793-805

Davis CA, Smith LM (1998) Ecology and management of migrant shorebirds in the playa lakes region of Texas. Wildl Monogr 140:1-45

De'ath G, Fabricius KE (2000) Classification and regression trees: a powerful yet simple technique for ecological data analysis. Ecology 8:3178-3192

Deppe JL, Rotenberry JT (2008) Scale-dependent habitat use by fall migratory birds: vegetation structure, floristics, and geography. Ecol Monogr 78:461-487

Detenbeck NE, Elonen CM, Taylor DL, Cotter AM, Puglisi FA, Sanville WD (2002) Effects of agricultural activities and best management practices on water quality of seasonal prairie pothole wetlands. Wetland Ecol Manag 10:335-354

Domin K (1928) The relations of the Tatra mountain vegetation to the edaphic factors of the habitat; a synecological study. Acta Bot Bohem 6(7):133-164

Environmental Systems Research Institute (1999-2004) ArcGIS (9.0). ESRI, Redlands

Farmer AH, Parent AH (1997) Effects of the broad scale on shorebird movements at spring migration stopovers. Condor 99:698-707

Fletcher RJ, Hutto RL (2008) Partitioning the multi-scale effects of human activity on the occurrence of riparian forest birds. Landscape Ecol 23:727-739

Haukos DA, Smith LM (2003) Past and future impacts of wetland regulations to playa ecology in the southern Great Plains. Wetlands 23:577-589

Henley JE, Harrison MS (2000) The Oklahoma wetlands reference guide. Oklahoma Conservation Commission, Oklahoma City

Holland JD, Bert DG, Fahrig L (2004) Determining the spatial scale of species' response to habitat. Bioscience $54: 227-233$
Hutto RL (1985) Seasonal changes in the habitat distribution of transient insectivorous birds in southeastern Arizona: competition mediated? Auk 102:120-132

(IPCC) Intergovernmental Panel on Climate Change (2007) Climate change 2007: the physical science basis. Cambridge University Press, Cambridge

Ives AR, Zhu J (2006) Statistics for correlated data: phylogenies, space, and time. Ecol Appl 16:20-32

Johnson WC, Werner B, Guntenspergen GR, Voldseth RA, Millett B, Naugle DE, Tulbure M, Carroll RWH, Tracy J, Olawsky C (2010) Prairie wetland complexes as landscape functional units in a changing climate. BioScience 60:128-140

Koper N, Schiemgelow FKA (2006a) A multi-scaled analysis of avian response to habitat amount and fragmentation in the Canadian dry mixed-grass prairie. Landscape Ecol 21:1045-1059

Koper N, Schiemgelow FKA (2006b) Effects of habitat management for ducks on target and nontarget species. J Wildl Manag 70:823-834

Lenth RV (2006) Java applets for power and sample size (Computer software). http://www.stat.uiowa.edu/ rlenth/ Power. Accessed 1 May 2007

Levin SA (1992) The problem of pattern and scale in ecology. Ecology 73:1943-1967

Lindenmayer DB (2000) Factors at multiple scales affecting distribution patterns and their implications for animal conservation-Leadbeater's Possum as a case study. Biodivers Conserv 9:15-35

Luo HR, Smith LM, Allen BL, Haukos DA (1997) Effects of sedimentation on playa wetland volume. Ecol Appl 7:247-252

Melles SJ, Badzinski D, Fortin M-J, Csillag F, Lindsay K (2009) Disentangling habitat and social drivers of nesting patterns in songbirds. Landscape Ecol 24:519-531

Moore FR (2000) Application of spatial models to stopover ecology of trans-gulf migrants. Stud Avian Biol 20:5-14

Morrison RIG (2006) Body transformations, condition, and survival in Red Knots Calidris canutus travelling to breed at Alert, Ellesmere Island, Canada. Ardea 94:607-618

Morrison RIG, Gill RE, Harrington BA, Skagen S, Page GW, Gratto-Trevor CL, Haig SM (2001) Estimates of shorebird populations in North America. Canadian Wildlife Service occasional paper, no. 104, Ottawa, Ontario

Naugle DE, Higgins KF, Nusser SM, Johnson WC (1999) Scaledependent habitat use in three species of prairie wetland birds. Landscape Ecol 14:267-276

Naugle DE, Johnson RR, Estey ME, Higgins KF (2000) A landscape approach to conserving wetland bird habitat in the prairie pothole region of eastern South Dakota. Wetlands 20:1-17

Niemuth ND, Estey ME, Reynolds RE, Loesch CR, Meeks WA (2006) Use of wetlands by spring-migrant shorebirds in agricultural landscapes of North Dakota's drift prairie. Wetlands 26:30-39

Oklahoma Climatological Survey (OCS) (2010) Mesonet (web application). The University of Oklahoma, Norman, Oklahoma. http://climate.mesonet.org/. Accessed 20 Sept 2010

Oklahoma Department of Wildlife Conservation (ODWC) (2006) Oklahoma comprehensive wildlife conservation 
strategy. Oklahoma City, Oklahoma. http://www.wildlife department.com/CWCS.htm. Accessed 20 Dec 2010

Petit DR (2000) Habitat use by landbirds along nearctic-neotropical migration routes: implications for conservation of stopover habitats. Stud Avian Biol 20:15-33

Pierisma T (1987) Hop, jump, or skip? Constraints on migration of Arctic waders by feeding, fattening, and flight speed. Limosa 60:185-194

R Development Core Team (2010) R: a language and environment for statistical computing. R Foundation for Statistical Computing, Vienna

Renfrew RB, Ribic CA (2008) Multi-scale models of grassland passerine abundance in a fragmented system in Wisconsin. Landscape Ecol 23:181-193

Ribeiro R, Carretero MA, Sillero N, Alarcos G, Ortiz-Santaliestra M, Lizana M, Llorente GA (2011) The pond network: can structural connectivity reflect on (amphibian) biodiversity patterns? Landscape Ecol 26:673-682

Ricklefs RE (1987) Community diversity: relative roles of regional and local processes. Science 235:167-171

Romero S, Campbell JF, Nechols JR, With KA (2009) Movement behavior in response to landscape structure: the role of functional grain. Landscape Ecol 24:39-51

Seaman DE, Powell RA (1996) An evaluation of the accuracy of kernel density estimators for home range analysis. Ecology 77:2075-2085

Skagen SK (2006) Migration stopovers and the conservation of arctic-breeding Calidridine sandpipers. Auk 123:313-322

Skagen SK, Knopf FL (1993) Toward conservation of midcontinent shorebird migrations. Conserv Biol 7:533-541

Skagen S K, Brown S, Johnson R (2005) Implications of different shorebird migration strategies for habitat conservation. USDA Forest Serv Gen Tech Rep PSW_GTR_191: $687-683$

Skagen SK, Granfors DA, Melcher CP (2008a) On determining the significance of ephemeral continental wetlands to North American migratory shorebirds. Auk 125:20-29

Skagen SK, Melcher CP, Haukos DA (2008b) Reducing sedimentation of depressional wetlands in agricultural landscapes. Wetlands 28:594-604

Smith LM, Haukos DA (2002) Floral diversity in relation to playa wetland area and watershed disturbance. Conserv Biol 16:964-974

Taft OW, Colwell MA, Isola CR (2002) Waterbird responses to experimental drawdowns: implications for the multispecies management of wetland mosaics. J Appl Ecol 39:987-1001

Thogmartin WE, Knutson MG (2007) Scaling local specieshabitat relations to the larger landscape with a hierarchical spatial count model. Landscape Ecol 22:61-75
Tilman D, Fargione J, Wolfe B, D’Antonio C, Dobson A, Howarth R, Schindler D, Schlesinger WH, Simberloff D, Swackhamer D (2001) Forecasting agriculturally driven global environmental change. Science 292:281-284

Turner MG (2005) (2005) Landscape ecology: what is the state of the science? Annu Rev Ecol Evol Syst 36:319-344

Turner MG, Gardner RH, O’Neill RV (2001) Landscape ecology in theory and practice: pattern and process. Springer, New York

Uchida Y, Inoue M (2010) Fish species richness in spring-fed ponds: effects of habitat size versus isolation in temporally variable environments. Freshw Biol 10:983-994

van der Valk AG, Pederson RL (2003) The SWACC decision and its implications for prairie potholes. Wetlands 23:590-596

Vergara PM, Armesto JJ (2009) Responses of Chilean forest birds to anthropogenic habitat fragmentation across spatial scales. Landscape Ecol 24:25-38

Warnock N, Haig SM, Oring LW (1998) Monitoring species richness and abundance of shorebirds in the Western Great Basin. Condor 100:589-600

Webb EB, Smith LM, Vrtiska MP, Lagrange TG (2010) Effects of local and landscape level variables on wetland habitat use during migration through the rainwater basin. J Wildl Manag 74:109-119

Wettstein W, Schmid B (1999) Conservation of arthropod diversity in montane wetlands: effect of altitude, habitat quality and habitat fragmentation on butterflies and grasshoppers. J Appl Ecol 36:363-373

Wheatley M, Johnson C (2009) Factors limiting our understanding of scale. Ecol Complex 6:150-159

Wiens JA (1989) Spatial scaling in Ecology. Funct Ecol 3:385-387

Woodhouse CA, Overpeck JT (1998) 2000 years of drought variability in the central United States. Bull Am Meteorol Soc 79:2693-2714

Worton BJ (1989) Kernel methods for estimating the utilization distribution in home range studies. Ecology 70:164-168

Wu J (2004) Effects of changing scale on landscape pattern analysis: scaling relations. Landscape Ecol 19:125-138

Wu J, Loucks OL (1995) From balance of nature to hierarchical patch dynamics: a paradigm shift in ecology. Q Rev Biol 70:439-466

Zuur AF, Ieno EL, Walker NJ, Saveliev AA, Smith GM (2009) Mixed effects models and extensions in ecology with R. Springer, New York 